\title{
Evidence that Increased Adrenal Glucocorticoid Release During Superovulation does not Impair Gonadal Responses in Crossbred Thai Dairy Cows
}

\author{
Jaruwan Khonmee ${ }^{1,2^{*}}$, Jureerat Sumretprasong ${ }^{1}$, Janine L. Brown ${ }^{3}$, \\ Kamraitip Lokham ${ }^{1}$, Wanchat Phakoetsuk ${ }^{1}$, and Veerasak \\ Punyapornwithaya $^{4}$
}

\begin{abstract}
${ }^{1}$ Department of Veterinary Bioscience and Veterinary Public Health, Faculty of Veterinary Medicine, Chiang Mai University, Chiang Mai 50100, Thailand ${ }^{2}$ Excellent Center in Veterinary Bioscience, Chiang Mai University, Chiang Mai 50100, Thailand

${ }^{3}$ Center for Species Survival, Smithsonian Conservation Biology Institute, Front Royal, VA 22630, USA

${ }^{4}$ Department of Food Animal Clinic, Faculty of Veterinary Medicine, Chiang Mai University, Chiang Mai 50100, Thailand

*Corresponding author. E-mail: jaruwan.khonmee@cmu.ac.th https//:doi.org/10.12982/CMUJNS.2020.0047
\end{abstract}

Received: September 19, 2019

Revised: November 9, 2019 Accepted: December 17, 2019

\section{ABSTRACT}

Embryo transfer is an important assisted reproductive technique to increase the efficacy of reproduction in dairy cattle, although responses to superovulation therapies remain inconsistent. Stress can negatively affect reproduction in farm animals, and could be a factor in compromising ovulation induction and embryo transfer success due to intensive handling procedures. This study evaluated ovulation rates, development of functional corpora lutea (CL), embryo quality, and fecal glucocorticoid (FGM) and fecal progestagen (FPM) metabolite concentrations in response to two FSH superovulation protocols in crossbred Thai dairy cows. Cows were administered decreasing doses of FSH (200 mg) administered over 4 or 6 days (n=3/treatment). All females ovulated based on FPM profiles, but numbers of $C L$ and embryos collected, and embryo quality varied across individuals. Nevertheless, similar numbers of transferable embryos ( 4 each) were obtained for both 4- and 6day FSH regimens. FGM concentrations during superovulation (Mid) (162.2 \pm $8.4 \mathrm{ng} / \mathrm{g})$ were greater than those before $(115.8 \pm 5.8 \mathrm{ng} / \mathrm{g})$ or after $(104.3 \pm 9.8)$ treatment $(P<0.05)$, but there was no treatment difference. Observed increases in FGM indicate that reproductive manipulation can induce acute stress 


\section{responses; however, there were no apparent adverse effects on reproductive responses or embryo quality.}

Keywords: Cow, Fecal glucocorticoids, Fecal progestagens, Stress, Superovulation

\section{INTRODUCTION}

Superovulation has been shown to increase the efficiency of embryo transfer and in vitro fertilization techniques in ungulate species, both domestic, such as sheep, goats (Cognié et al., 2003; Rahman et al., 2008) and cattle (Bó and Mapletoft, 2014), and non-domestic, including red deer (Cervus elaphus) (Bainbridge et al., 1995) and brown brocket deer (Mazama gouazoubira) (Zanetti et al., 2014). Twice daily intramuscular injections of decreasing folliclestimulating hormone (FSH) doses over 4 days (total dose of 260-300 mg) has been a standard superovulation protocol for crossbred dairy cows in Thailand for more than 20 years (Sumretprasong et al., 2008; Bó and Mapletoft, 2014). It is typically combined with use of a progesterone-releasing device (CIDR-B) inserted intravaginally, which remains in place until the end of FSH treatment (Bó et al., 2008). PGF $_{2 \alpha}$ administration on the third day of FSH treatment has further been incorporated into the protocol to synchronize estrus, followed by artificial insemination (AI) at 12, 24 and 36 hours after standing heat. Finally, $\mathrm{GnRH}$ often is administered at the time of the first AI to ensure ovulation takes place.

A follicular wave is defined as the synchronous growth of a group of $8-41$ small follicles $(3-4 \mathrm{~mm}$ in diameter) from which a single follicle is selected to become dominant (Adams et al., 2008). This growth in cattle is FSHdependent, with subordinate follicles becoming atretic when FSH concentrations are below the threshold needed to sustain development. Superstimulatory treatments with exogenous FSH prevent the regression of subordinate follicles, allowing small follicles to be recruited into the cohort of growing follicles (Bó et al., 2008). Although FSH is generally administered over 4 days, it has been proposed that longer treatments could increase recruitment by providing more time for smaller follicles to reach an ovulatory size and acquire the capacity to ovulate (Mapletoft and Bó, 2013). Assuming a growth rate of $1-2 \mathrm{~mm}$ per day, these follicles could be recruited by adding $2-3$ days to the treatment protocol (Mapletoft and Bó, 2013). Indeed, lengthening the treatment protocol from 4 to 7 days without increasing the total amount of FSH administered increased the number of ovulations and transferable embryos in beef cows (García Guerra et al., 2012).

Problems with superovulation regimens often are related to highly variable ovarian responses, both within and across species and individuals (Cognié et al., 
2003), due to factors such as cycle stage, age, weight, and genetics (Senthil Kumar et al., 2003; Zanetti et al., 2014). Cows with a low number of follicles entering the wave typically respond poorly, even when the treatments are initiated at the time of follicular emergence (Bó et al., 2008). It is also possible that stress induced by manipulation during superovulation and embryo collection procedures may negatively affect ovarian function (González et al., 2008; Macedo et al., 2011). Previous studies have demonstrated a relationship between stress and reproductive performance related to handling and heat stress (Bova et al., 2014), poor housing and nutrition (Lee, 1993), transportation (Morrow et al., 2002), and human-animal interactions (Macedo et al., 2011) that can increase cortisol secretion. One widely used method to monitor stress is the analysis of glucocorticoid metabolites excreted in feces (Morrow et al., 2002; Khonmee et al., 2014), which avoids the need to handle study subjects that in itself can induce an adrenal response.

In this study, we hypothesized that superovulation procedures may induce a stress response in dairy cows, which could adversely affect ovulatory responses. Specifically, the goal was to determine if the addition of two more days of FSH treatment would be more of a stressor than the traditional 4-day superovulation regimen. Thus, the aims of this study were to: 1) compare the efficacy of two FSH injection regimens on ovarian responses, including numbers of corpora lutea (CL), embryo quality, and fecal progestagen metabolite (FPM) patterns; 2) determine if superovulation, $\mathrm{AI}$ and embryo collection procedures increase fecal glucocorticoid metabolite (FGM) concentrations; and 3) assess if adrenal glucocorticoid responses would be greater for a 6- versus a 4-day FSH injection schedule.

\section{MATERIALS AND METHODS}

\section{Ethics statements}

This study was approved by the Faculty of Veterinary Medicine, Chiang Mai University, Animal Care and Use Committee (FVM-ACUC) (Permit Number S18/2558). Six adult Thai cross-bred cows (aged 16 - 17 months, weighing $280-300 \mathrm{~kg}$ ) were housed in individual covered stalls (size $36 \mathrm{~m}^{2}$; $8 \mathrm{~m} \times 10 \mathrm{~m})$ at the Faculty of Agriculture, Chiang Mai University in Thailand (latitude $18^{\circ} 47^{\prime} \mathrm{N}$, longitude $98^{\circ} 59^{\prime} \mathrm{E}$, altitude $330 \mathrm{~m}$ ).

\section{Estrus synchronization and superovulation treatment}

The experimental design is illustrated in Figure 1. Six cows were allocated to two treatment groups, each inserted with an intravaginal device containing 1.38 $\mathrm{g}$ of progesterone (CIDR- type $\mathrm{B}^{\circledR}$, Controlled Internal Drug Release, Pfizer Animal Health, USA) followed by a total of $200 \mathrm{mg}$ FSH (Folltropin-V ${ }^{\circledR}$; Bioniche Animal Health; Canada) administered over 4 (Treatment 1, n=3) or 6 (Treatment 2, $\mathrm{n}=3)$ days. Cows then were given $250 \mu \mathrm{g}$ i.m. of $\mathrm{PGF}_{2 \alpha}(250 \mu \mathrm{g}$ 
cloprostenol; $1 \mathrm{~mL}$ Estrumate ${ }^{\circledR}$; Schering Plough Animal Health, USA) and observed for behavioral estrus. The first AI was conducted 12 hours after standing heat followed by i.m. injection of $0.02 \mathrm{mg}$ GnRH (Receptal ${ }^{\circledR}$, MSD Animal Health, Wellington, New Zealand), with two additional inseminations 12 hours apart. All AIs were conducted with frozen semen $(0.25 \mathrm{ml}, \geq 40 \%$ motility, $\sim 20 \times$ $\left.10^{6} \mathrm{sperm} / \mathrm{straw}\right)$. Ovarian responses were determined by manual palpation of the ovaries per rectum, and the number of CL and large follicles (over $5 \mathrm{~mm}$ ) were recorded. For embryo flushing, animals were restrained in a crush with a head bail and given an epidural ( $3 \mathrm{ml}$, Xylocaine ${ }^{\circledR} 2 \%$, OLIC Ltd., Thailand). Embryos were collected non-surgically 7 days after AI using a commercial embryo recovery solution (ViGro Complete Flushing Solution; Bioniche Animal Health, USA). Following IETS guidelines, embryos were defined as transferable (grades 1,2 and 3) or freezable (grades 1 and 2). On Day 8, $\mathrm{PGF}_{2 \alpha}$ was given to lyse existing CLs and prevent implantation of any remaining embryos.

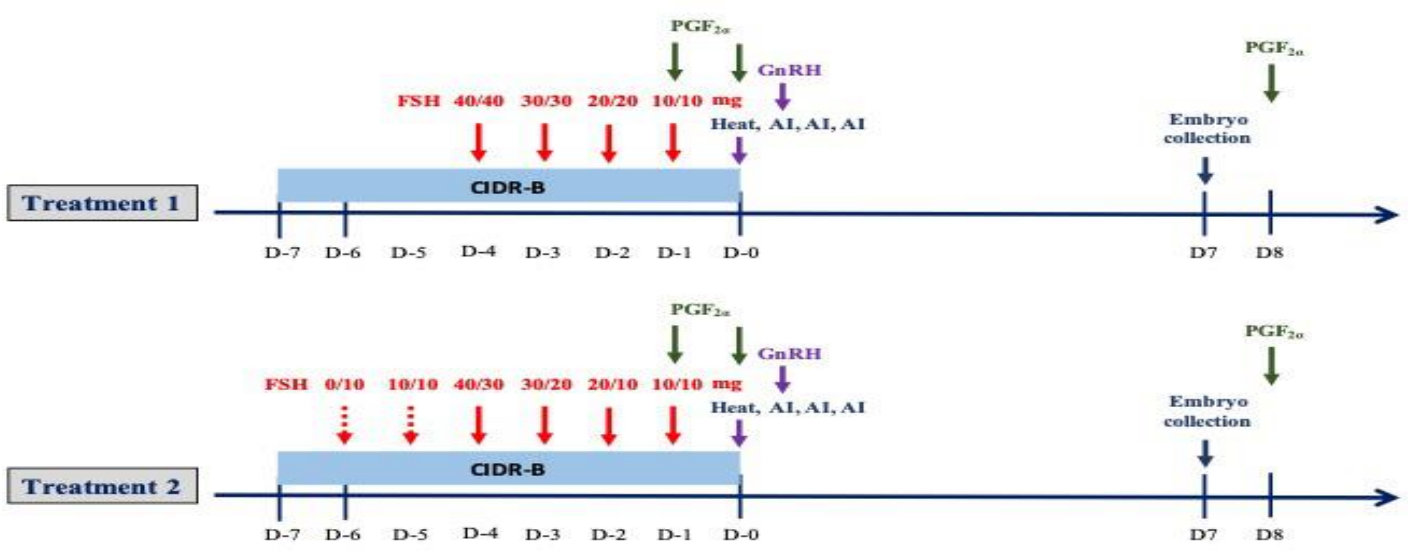

Figure 1. Schematic of the two superovulation protocols used in this study $(\mathrm{n}=3$ cows each). Injections of FSH were given twice daily (0800 and $1600 \mathrm{~h}$ ) for 4 days in Treatment 1 , and 6 days in Treatment 2, with $250 \mu \mathrm{g}$ of $\mathrm{PGF}_{2 \alpha}$ given on day $-1(1600 \mathrm{~h})$ and day $-2(0800 \mathrm{~h})$. Repeated AI were performed at $12 \mathrm{~h}$ intervals after standing heat was detected; i.m. injection of GnRH $(0.02 \mathrm{mg})$ was given after the first AI. Embryos were collected 7 days after AI, followed by PGF $_{2 \alpha}$ given the morning of Day 8.

\section{Fecal sample collection, processing and hormone analysis}

Fresh fecal samples $(\sim 30 \mathrm{~g})$ were collected between 08:30 and 09:30 hours by rectal collection over three time periods: 3 days/week for 30 days before superovulation (Pre), daily for 17 days during superovulation and embryo collection (Mid), and 3 days/week for 30 days after embryo collection (Post). Samples were stored at $-20^{\circ} \mathrm{C}$ until extracted for FGM as described previously (Khonmee et al., 2016). 
Fecal FGM and FPM metabolites were quantified using double-antibody enzyme immunoassays (EIA) that relied on a polyclonal rabbit anticorticosterone antibody (CJM006) and monoclonal mouse anti-progesterone antibody (CL-425), respectively, that crossreact with relevant metabolites. Plates were coated with anti-rabbit IgG $(10 \mu \mathrm{g} / \mathrm{ml}$; Cat. No. A009, Arbor Assays, Ann Arbor, MI) or anti-mouse IgG $(10 \mu \mathrm{g} / \mathrm{ml}$; Cat. No. A008, Arbor Assays, Ann Arbor, MI) in coating buffer (Cat. No. X108, 20X, Arbor Assays, Ann Arbor, MI) by adding $150 \mu \mathrm{l}$ to each well of a 96-well microtiter plate (Cat. No. 07-20039, Fisher Scientific, Pittsburgh, PA) followed by incubation at room temperature (RT) for 15-24 hours. Corticosterone (50 $\mu$ l, range $3.9-1,000 \mathrm{pg} /$ well; C2505 Sigma-Aldrich, Dorset, UK)or progesterone $(50 \mu \mathrm{l}$, range $0.78-200 \mathrm{pg} /$ well; P01301 Sigma-Aldrich, Dorset, UK) standards and samples diluted in buffer (50 $\mu 1,1: 8$ dilution for FGM, 1:70-1:800 dilution for FPM), were combined with steroid-HRP $(25 \mu \mathrm{l} ; 1: 250,000$ dilution for corticosterone, 1:40,000 dilution for progesterone; U.C. Davis, CA) followed by addition of $25 \mu \mathrm{l}$ of primary antibody (1:100,000 dilution for corticosterone, 1:75,000 dilution for progesterone), except NSB wells, and incubated at RT for 1 hour. Plates were washed four times with wash buffer before addition of $100 \mu 1$ of TMB substrate solution (Ward Medic, Bangkok, Thailand). After incubation for $45-60 \mathrm{~min}$ at RT without shaking, the absorbance was measured at $620 \mu \mathrm{m}$ (TECAN Sunrise ${ }^{\mathrm{TM}}$ microplate reader, Salzburg, Austria) until the optical density approached 0.9 and then stop solution $(0.16 \mathrm{M}$ sulfuric acid) was added $(50 \mu \mathrm{l})$ to each well. The absorbance was measured at $405 \mu \mathrm{m}$ (TECAN Sunrise ${ }^{\mathrm{TM}}$ microplate reader, Salzburg, Austria).

The EIAs were validated for cow feces by demonstrating parallelism between serial dilutions of pooled extracts and the respective standard curves (Pearson's correlation coefficient for FGM and FPM; $r=0.99$ and $r=0.99$, respectively). Addition of unlabeled standard to pooled fecal extracts before extraction resulted in significant mass recoveries $\left(\mathrm{y}=0.27 \mathrm{x}-0.35, \mathrm{R}^{2}=0.94\right.$ for FGM, and $\mathrm{y}=1.17 \mathrm{x}-6.41, \mathrm{R}^{2}=0.98$ for FPM; $P<0.05$ ). Extraction efficiencies were $80-90 \%$ for both hormones. Assays were biologically validated by showing a marked increase in FGM concentrations in a cow that was moved to another barn and restrained on two occasions for rectal palpation by students (Figure 2), and FPM in cows after ovulation (Figure 4). Assay sensitivities were $0.78 \mathrm{ng} / \mathrm{ml}$ and $0.015 \mathrm{ng} / \mathrm{ml}$ at 90 binding for the corticosterone and progesterone EIAs, respectively. Inter-assay CVs were $<15 \%$ based on binding of high $(30 \%)$ and low $(70 \%)$ control samples. All samples were re-analyzed if the duplicate CV was $>10 \%$; thus, intra-assay CVs were $<10 \%$. Data are expressed as ng/g dry feces. 


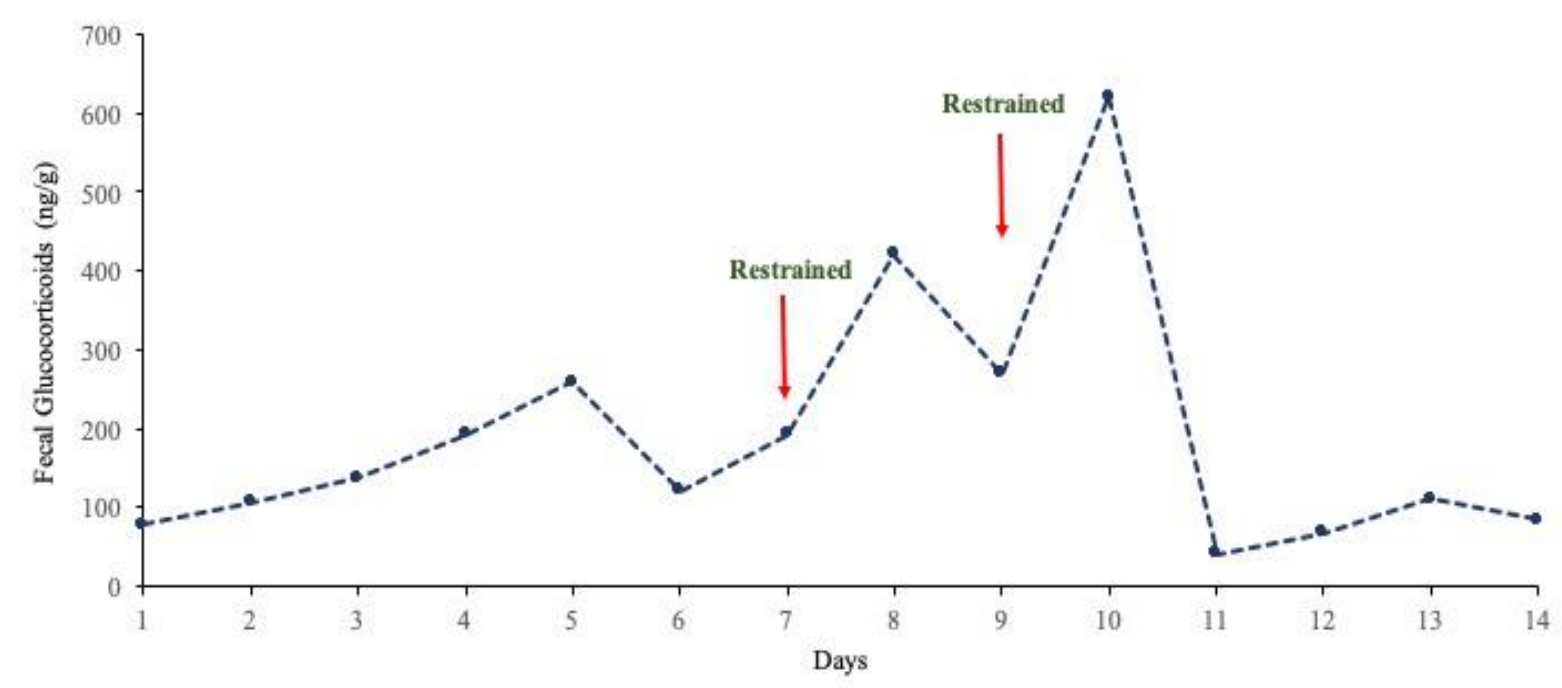

Figure 2. Concentrations of FGM after moving a female to a different building for rectal palpation by agriculture students.

\section{Statistical analyses}

Data are reported as mean \pm standard error of mean (SEM). Differences in number of CL and numbers of eggs in each protocol were analyzed using Approximately Two Sample Fisher-Pitman Permutation Tests with package survival (Therneau and Lumley, 2016) because of small sample sizes and data that were not normally distributed. One cow in Treatment 1 produced only one $\mathrm{CL}$ and embryo collection was not attempted, resulting in $\mathrm{N}=2$, so no statistical analysis was performed for differences in mean embryos collected between groups.

Baseline FGM concentrations were determined by an iterative process in which high values that exceeded the mean +1.5 times the standard deviation were excluded and the mean recalculated until no values exceeded the mean +1.5 standard deviation (Brown et al., 2001). Baseline values were those remaining after exclusion of all high values. Concentration differences in FGM concentrations for each treatment group across the three periods (Pre, Mid, Post), and between periods associated with superovulation versus $\mathrm{AI}$ and $\mathrm{GnRH}$ injections were analyzed using a generalized least square (GLS) method for repeated measures data by R 3.2.3 (R Development Core Team, 2017) with nlme package $3.1-122$ (Pinheiro et al., 2015). The structure of the covariance pattern for GLS was defined as a compound symmetry followed by a Tukey's test for the multiple comparison adjustment. For all statistical tests, the significance level $(\alpha)$ was set at 0.05 . 


\section{RESULTS}

Ovarian responses to the two superovulation protocols are presented in Table 1. All cows responded with ovulations; however, one female in Treatment 1 produced only one CL, and embryo collection was not attempted. Because of the large variability in responses, there was no difference in mean numbers of CL collected between the two treatment groups $(P>0.05)$. Omitting the one cow with a poor response, the other two in Treatment 1 produced 18 and 22 CL, which was double that observed for cows in Treatment 2. Furthermore, all embryos resulting from ovulations were recovered from cows in Treatment 1, compared to only 54.8 $\pm 6.4 \%$ for those in Treatment 2 . However, embryo quality was lower in Treatment 1 , resulting in only $21.5 \%$ being considered transferable, as compared to $75.0 \%$ for Treatment 2 . Most of the embryos collected in Treatment 1 were degenerated $(n=20)$ with seven unfertilized ova also collected. By contrast, most embryos from Treatment 2 were of good quality and considered transferable.

Table 1. Mean \pm SEM superovulatory responses (range) in six cows subjected to two FSH injection regimens.

\begin{tabular}{|c|c|c|c|}
\hline & $\begin{array}{l}\text { Treatment } 1 \\
\quad(\mathbf{N}=3)\end{array}$ & $\begin{array}{l}\text { Treatment } 2 \\
\quad(\mathbf{N}=3)\end{array}$ & P-value \\
\hline Mean CL/cow (range) & $13.7 \pm 6.4(1-22)$ & $9.7 \pm 0.7(9-11)$ & 0.10 \\
\hline Total number of CL observed ${ }^{\#}$ & 41 & 29 & \\
\hline Total number of embryos collected ${ }^{\#}$ & 40 & 16 & \\
\hline Mean embryos collected (range) & $20.0 \pm 1.6(18-22)$ & $5.3 \pm 0.7(4-6)$ & NA \\
\hline Mean transferable embryos (range) & $4.3 \pm 2.2(6-7)^{\# \#}$ & $4.0 \pm 0.6(3-5)$ & 0.19 \\
\hline Total number of transferable embryos & 13 & 12 & \\
\hline
\end{tabular}

There were no differences in overall mean FGM and FPM concentrations between the two treatment groups $(P>0.05)$; therefore, data were pooled for further analysis. Mean concentrations were higher during the Mid (162.2 \pm 8.4 , $1,887.9 \pm 364.1 \mathrm{ng} / \mathrm{g})$ as compared to Pre and Post $(115.8 \pm 5.8,434.0 \pm 41.5$ $\mathrm{ng} / \mathrm{g} ; 104.3 \pm 9.8,480.0 \pm 74.9 \mathrm{ng} / \mathrm{g})$ periods for both FGM and FPM $(P<0.05)$, respectively. Mean longitudinal FGM and FPM patterns are shown in Figures 3 and 4. Concentrations of both were elevated in response to superovulation, and again in samples after AI and embryo collection. Overall FGM responses associated with each these two procedures were similar $(P>0.05)$ (Figure 3). During the Mid period, there were no differences in mean FGM and FPM 
concentrations between Treatments 1 and 2, or in mean peak FGM and FPM concentrations (Figures 3 and 4). However, one cow in Treatment 1 that produced only one CL, and was not subjected to embryo collection (Figure 5) exhibited an abnormal FPM pattern, with minimal concentrations during CIDR treatment and a poor ovulatory response. She also exhibited significant elevations in FGM and FPM during the Post period, which at least for FGM was likely due to being restrained for rectal palpations (Figures 2 and 5). There also was no correlation between CL number and peak FPM concentrations for all animals combined $(p=0.14)$.

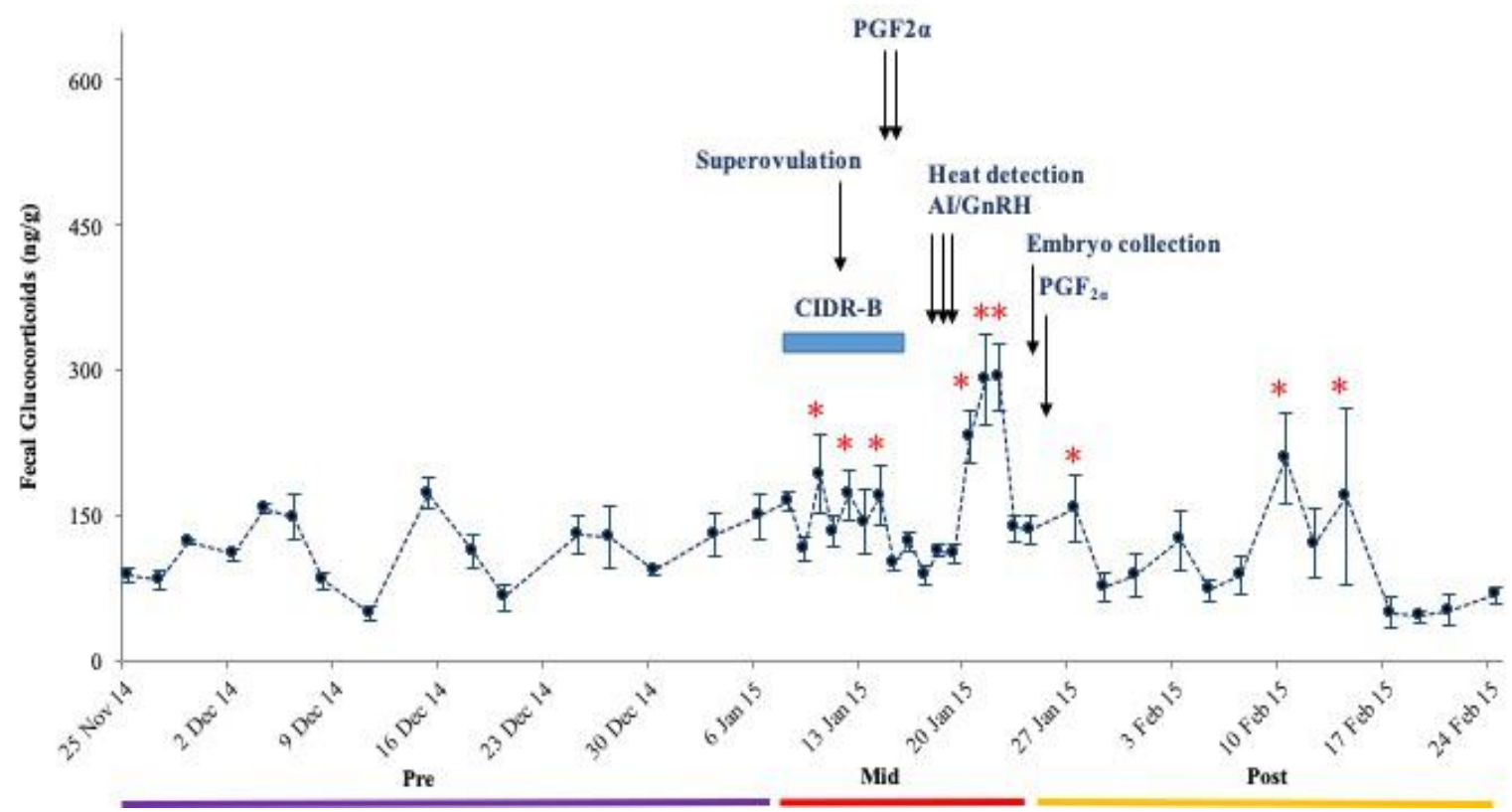

Figure 3. Mean ( \pm SEM) longitudinal FGM concentrations in six dairy cows. Before, during and after superovulation, AI and embryo collection procedures.

Note: *Concentrations are higher than the Pre period baseline. 


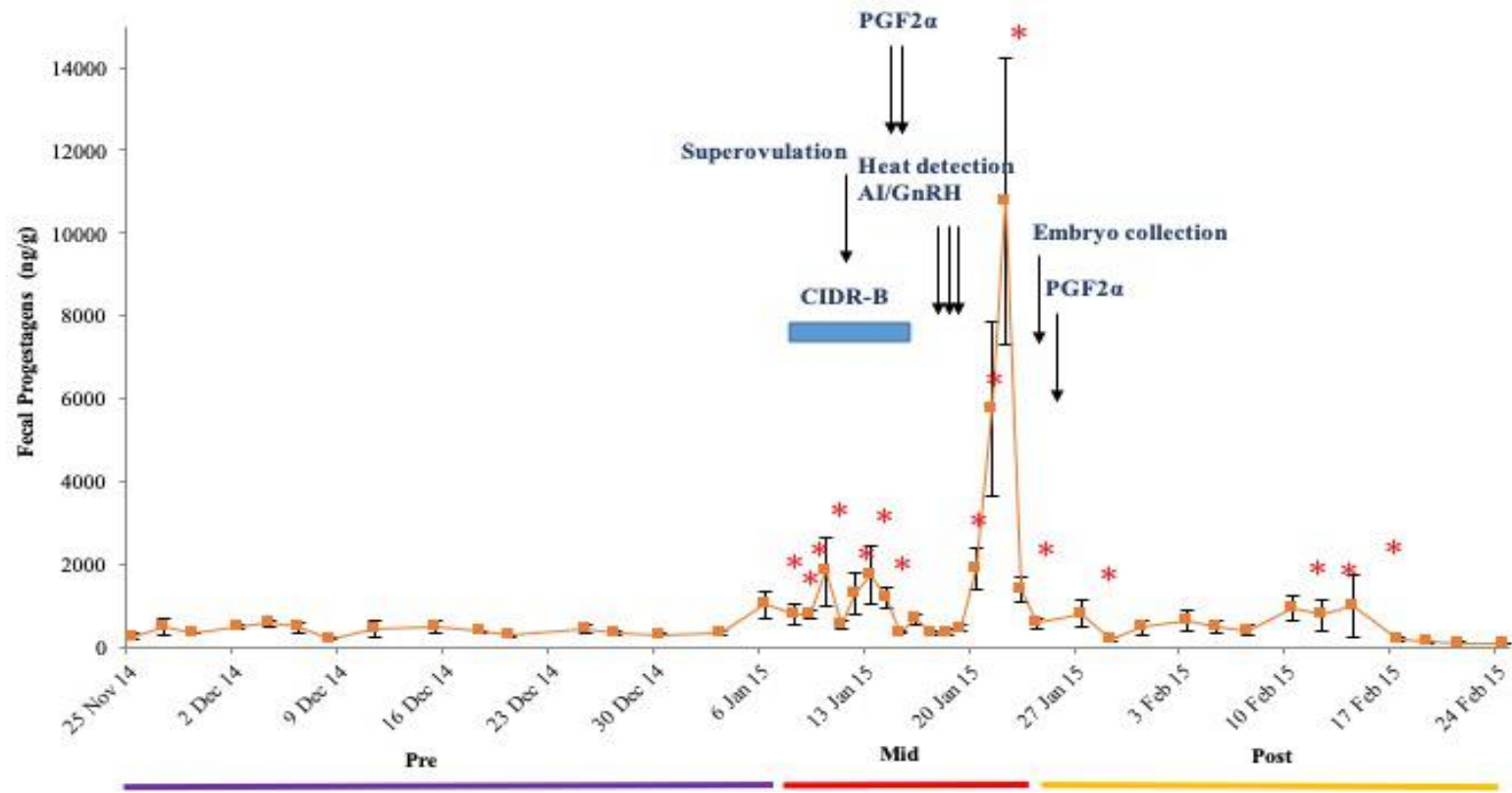

Figure 4. Mean ( \pm SEM) longitudinal FPM concentrations in six dairy cows. Before, during and after superovulation, AI and embryo collection procedures.

Note: ${ }^{*}$ Concentrations are higher than the Pre period baseline.

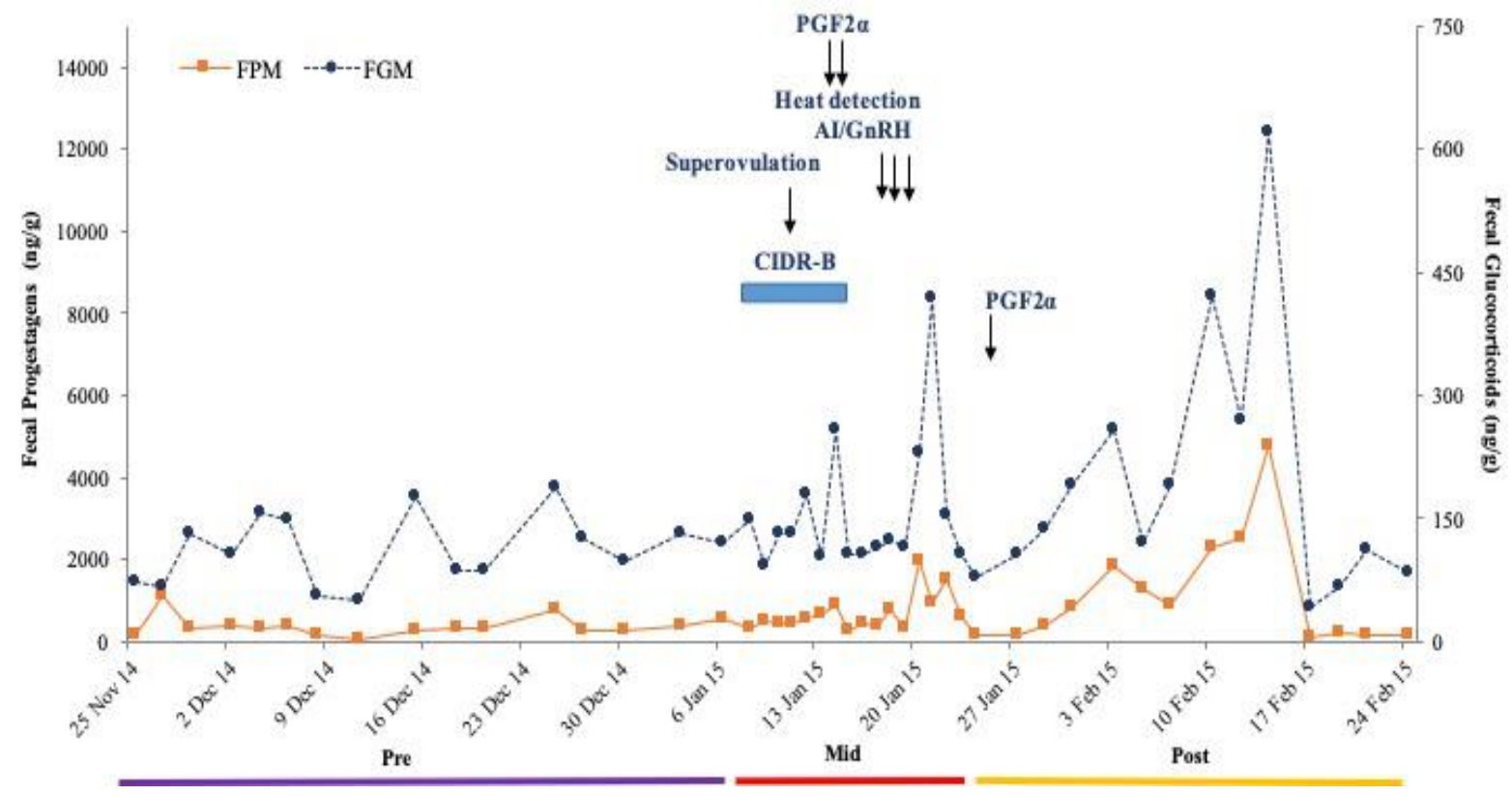

Figure 5. Longitudinal FGM and FPM profiles of a dairy cow in Treatment 1 , before, during and after superovulation, AI and embryo transfer procedures. 


\section{DISCUSSION}

In this study, both 4- and 6-day superovulation regimens caused an ovulatory response, although they varied among cows. One female in Treatment 1 produced only one CL, and had exhibited lower FPM concentrations during CIDR treatment, providing a possible explanation for the poor response. The FPM response after ovulation also was poor. A greater number of embryos was collected in the other two cows treated for 4 days, although half were degraded. This resulted in similar mean numbers of transferable embryos between the two treatment groups, which indicates the proportion of quality embryos was greater for the extended FSH treatment, at least in this preliminary study. In examining adrenal responses, all animals exhibited acute elevations in FGM during superovulation, but 6 days of FSH injections was no more stressful than the 4-day protocol, and concentrations returned to baseline shortly after manipulations in both groups. Thus, handling stress associated with superovulation likely has a minimal effect on ovulatory responses in Thai dairy cattle.

A total dose of $200 \mathrm{mg}$ FSH was used in both treatments, which is less than more conventional regimens that typically use $300-400 \mathrm{mg}$ (Bó et al., 2008 ; García Guerra et al., 2012). Still, ovulation rates were high (9-22 CL/cow, excluding the cow with only one ovulation), and comparable to those reported in other studies (12 to 15 CL) (Bó et al., 2008; Sumretprasong et al., 2008; Bó and Mapletoft, 2014). Numbers of transferable embryos also were acceptable, averaging $4 / \mathrm{cow}$ in this study, as compared to $3-7 / \mathrm{cow}$ in those reports. The similarity in numbers of $\mathrm{CL}$ and transferable embryos per cow between treatments suggests that adding two more days of stimulation, without increasing the total dose of FSH, had little effect on follicle recruitment. Data also indicate that a lower FSH dose $(200 \mathrm{mg}$ ) can be used without affecting embryo yield in Thai cattle. In fact, excess gonadotropins are not beneficial to embryo production (Yaakub et al., 1998). Evidence suggests that Bos indicus cattle are more sensitive to FSH, and our Thai cattle are hybrids of B. taurus and B. indicus (Sumretprasong et al., 2008). Thus, reducing the FSH dose and days of injections can minimize the cost of conducting embryo transfer without compromising results.

Distinct increases in glucocorticoid concentrations associated with superovulation and GnRH administration and/or AI have been shown in other studies; e.g., hair (Biancucci et al., 2016) and serum (Yavas et al., 1996) cortisol in beef cows; FGM in brown brocket deer (Zanetti et al., 2014) and Persian onager (Equus hemionus onager) (Wagman et al., 2015); and plasma cortisol in Mohor gazelle (Gazella dama mhorr) (González et al., 2008). In our study, concentrations of FGM were higher during reproductive manipulation compared to the Pre baseline in both groups, although there were no differences in the adrenal response for animals that received a total of 12 compared to only eight 
FSH injections. FGM concentrations remained elevated for about 5 days after each procedure before returning to baseline. In other ruminants, glucocorticoids reached baseline concentrations within hours to several days (Morrow et al., 2002) after a transport stressor. In other ungulates, high levels of adrenal corticosteroids during the follicular phase can disrupt follicular development (Peters and Lamming, 1986) by inhibiting the LH surge and/or affect oocyte competence (González et al., 2008), resulting in lower receptor acquisition and, consequently, lower responsiveness to LH (Lopez-Diaz and Bosu, 1992). Despite the elevated FGM observed in this study, concentrations apparently were not high enough to inhibit gonadotropin secretion and subsequent reproductive function based on the ovulatory responses.

Higher ovulation rates have been associated with increased progesterone concentrations because of increased luteal tissue mass [cows (Wiltbank et al., 2012); deer (Zanetti and Duarte, 2012)]. However, there was no correlation between CL number and FPM production in the present study. The pattern of FPM also was not influenced by elevated glucocorticoids during the procedures, similar to González et al. (González et al., 2008). As previously reported, administration of cloprostenol 14 days after superovulation treatment resulted in a rapid destruction of luteal tissue and return to baseline FPM concentrations within 72 hours (Zanetti and Duarte, 2012; Zanetti et al., 2014), which is necessary to prevent the implantation of any remaining embryos.

\section{CONCLUSION}

Ovulatory responses and embryo quality varied across individuals, although similar numbers of transferable embryos were collected after both 4and 6-day FSH treatments. FGM levels were increased during manipulation, but there was no difference between the two FSH injection protocols in stress responses. Increased FGM levels indicate that handling may be a cause of acute stress, but not enough to have an adverse effect on subsequent ovulation or embryo quality.

\section{ACKNOWLEDGEMENTS}

This study was supported by the Faculty of Veterinary Medicine, Chiang Mai University (grant number 08/2559). The authors are also grateful for research funding from the Excellent Center in Veterinary Bioscience, Chiang Mai University, Chiang Mai, Thailand [grant number 2561]. The authors extend gratitude to the Faculty of Agriculture, Chiang Mai University for housing the cows, and their assistance in sample collection. We are also grateful to Treepradab Norkaew, Pallop Tankaew in the endocrinology laboratory at the Faculty of Veterinary Medicine, Chiang Mai University for technical support. 


\section{REFERENCES}

Adams, G.P., Jaiswal, R., Singh, J., and Malhi, P. 2008. Progress in understanding ovarian follicular dynamics in cattle. Theriogenology. 69(1): 72-80. https://doi.org/10.1016/j.theriogenology.2007.09.026

Bainbridge, D.R.J., Chapple, D., Loudon, A.S.I., and Jabbour, H.N. 1995. Immunoneutralization with a monoclonal antibody attenuates the superstimulatory effects of PMSG on endocrine and ovarian responses in red deer (Cervus elaphus). Theriogenology. 8: 1339-1350. https://doi.org/ 10.1016/0093-691X(95)00118-R

Biancucci, A., Sbaragli, T., Comin, A., Sylla, L., Monaci, M., Peric, T., and Stradaioli, G. 2016. Reducing treatments in cattle superovulation protocols by combining a pituitary extract with a $5 \%$ hyaluronan solution: is it able to diminish activation of the hypothalamic pituitary adrenal axis compared to the traditional protocol? Theriogenology. 85: 914-921. https://doi.org/ 10.1016/j.theriogenology.2015.10.041

Bó, G.A., Guerrero, D.C., and Adams, G.P. 2008. Alternative approaches to setting up donor cows for superstimulation. Theriogenology. 69(1): 81-87. https://doi.org/10.1016/j.theriogenology.2007.09.005

Bó, G.A., and Mapletoft, R.J. 2014. Historical perspectives and recent research on superovulation in cattle. Theriogenology. 81: 38-48. https://doi.org/ 10.1016/j.theriogenology.2013.09.020

Bova, T.L., Chiavaccini, L., Cline, G.F., Hart, C.G., Matheny, K., Muth, A.M., Voelz, B.E., Kesler, D., and Memili, E. 2014. Environmental stressors influencing hormones and systems physiology in cattle. Reproductive Biology and Endocrinology. 12: 58. https://doi.org/10.1186/1477-7827$12-58$

Brown, J.L., Bellem, A.C., Fouraker, M., Wildt, D.E., and Roth, T.L. 2001. Comparative analysis of gonadal and adrenal activity in the black and white rhinoceros in North America by noninvasive endocrine monitoring. Zoo Biology. 20: 463-486. https://doi.org/10.1002/zoo.10028

Cognié, Y., Baril, G., Poulin, N., and Mermillod, P. 2003. Current status of embryo technologies in sheep and goat. Theriogenology. 59(1): 171-188. https://doi.org/10.1016/S0093-691X(02)01270-0

García Guerra, A., Tribulo, A., Yapura, J., Singh, J., and Mapletoft, R.J. 2012. Lengthening the superstimulatory treatment protocol increases ovarian response and number of transferable embryos in beef cows. Theriogenology. 78: 353-360. https://doi.org/10.1016/j.theriogenology. 2012.02.010 
González, R., Berlinguer, F., Espeso, G., Ariu, F., del Olmo, A., Garde, J.J., Gomendio, M., Ledda, S., and Roldan, E.R.S. 2008. Use of a neuroleptic in assisted reproduction of the critically endangered Mohor gazelle (Gazella dama mhorr). Theriogenology. 70: 909-922. https://doi.org/ 10.1016/j.theriogenology.2008.05.052

Khonmee, J., Brown, J.L., Rojanasthien, S., Aunsusin, A., Thumasanukul, D., Kongphoemphun, A., Siriaroonrat, B., Tipkantha, W., Punyapornwithaya, V., and Thitaram, C. 2014. Gender, season and management affect fecal glucocorticoid metabolite concentrations in captive Goral (Naemorhedus griseus) in Thailand. PLOS ONE. 9: e91633. https://doi.org/10.1371/ journal.pone.0091633

Khonmee, J., Vorawattanatham, N., Pinyopummin, A., Thitaram, C., Somgird, C., Punyapornwithaya, V., and Brown, J.L. 2016. Assessment of faecal glucocorticoid metabolite excretion in captive female fishing cats (Prionailurus viverinus) in Thailand. Conservation Physiology. 4. https:// doi.org/10.1093/conphys/cow021

Lee, C.N. 1993. Environmental stress effects on bovine reproduction. Veterinary Clinics of North America: Food Animal Practice. 9: 263-273.https://doi. org/10.1016/S0749-0720(15)30645-9

Lopez-Diaz, M.C., and Bosu, W.T.K. 1992. A review and an update of cystic ovarian degeneration in ruminants. Theriogenology. 37: 1163-1183. https://doi.org/10.1016/0093-691X(92)90173-O

Macedo, G.G., Zúccari, C.E.S.N., Abreu, U.G.P. de, Negrão, J.A., and Silva, E.V. da C. e. 2011. Human-animal interaction, stress, and embryo production in Bos indicus embryo donors under tropical conditions. Tropical Animal Health and Production. 43: 1175-1182. https://doi.org/10.1007/s11250011-9820-6

Mapletoft, R., and Bó, G.A. 2013. Innovative strategies for superovulation in cattle. Animal Reproduction Science. 10: 174-179.

Morrow, C.J., Kolver, E.S., Verkerk, G.A., and Matthews, L.R. 2002. Fecal glucocorticoid metabolites as a measure of adrenal activity in dairy cattle. General Comparative Endocrinology. 126: 229-241. https://doi.org/10. 1006/gcen.2002.7797

Peters, A.R., and Lamming, G.E. 1986. Regulation of ovarian function in the post partum cow: an endocrine model. Veterinary Record. 118(9): 236-239. https://doi.org/10.1136/vr.118.9.236

Pinheiro, J., Bates, D., DebRoy, S., and Sarkar, D. 2015. The R development core team nlme: linear and nonlinear mixed effects models. $\mathrm{R}$ package version. 3:1-122.

R Development Core Team. 2017. R: A language and environment for statistical computing. R Foundation for statistical computing. [Internet]. [Cited 2017 January 1]. Vienna, Austria: R Foundation for Statistical Computing. Available from: http://www.r-project.org/ 
Rahman, A.N.M.A., Abdullah, R.B., and Wan-Khadijah, W.E. 2008. Estrus synchronization and superovulation in goats: a review. Journal of Biology Science. 8: 1129-1137. https://doi.org/10.3923/jbs.2008.1129.1137

Senthil Kumar, P., Saravanan, D., Rajasundaram, R.C., Selvaraju, M., and Kathiresan, D. 2003. Serum oestradiol and progesterone profiles and their relationship with superovulatory responses in Tellicherry goats treated with eCG and FSH. Small Ruminant Research. 49: 69-77. https://doi. org/10.1016/S0921-4488(03)00071-3

Sumretprasong, J., Leangcharuen, N., Thungsanthia, A., and Thijae, K. 2008. Dose response to superovulation in Thai dairy cattle. Proceeding of $15^{\text {th }}$ Congress FAVA. October 27-30. Bangkok, Thailand.

Therneau, T.M., Lumley, T. 2016. The R development core team survival. R package version. 3: 1-122.

Wagman, J.D., Wolfe, B.A., and Schook, M.W. 2015. The effect of fluphenazine decanoate on glucocorticoid production, reproductive cyclicity, and the behavioral stress response in the Persian onager (Equus hemionus onager). Zoo Biology. 34: 525-534. https://doi.org/10.1002/zoo.21250

Wiltbank, M.C., Souza, A.H., Giordano, J.O., Nascimento, A.B., Vasconcelos, J.M., Pereira, M.H.C., Fricke, P.M., Surjus, R.S., Zinsly, F.C.S., Carvalho, P.D., et al. 2012. Positive and negative effects of progesterone during timed AI protocols in lactating dairy cattle. Animal Reproduction. 9: 231-241.

Yaakub, H., Duffy, P., O'Callaghan, D., and Boland, M.P. 1998. Effect of timing of oestradiol benzoate injection relative to gonadotropin treatment on superovulatory response, and on embryo yield and quality in beef heifers. Animal Reproduction Science. 52: 191-204. https://doi.org/10.1016/ S0378-4320(98)00106-7

Yavas, Y., de Avila, D.M., and Reeves, J.J. 1996. Trucking stress at breeding does not lower conception rate of beef heifers. Theriogenology. 45: 623632. https://doi.org/10.1016/0093-691X(95)00408-Z

Zanetti, E. dos S., and Duarte, J.M.B. 2012. Comparison of three protocols for superovulation of brown brocket deer (Mazama gouazoubira). Zoo Biology. 31: 642-655. https://doi.org/10.1002/zoo.20428

Zanetti, E.S., Munerato, M.S., Cursino, M.S., and Duarte, J.M.B. 2014. Comparing two different superovulation protocols on ovarian activity and fecal glucocorticoid levels in the brown brocket deer (Mazama gouazoubira). Reproduction Biology Endocrinology. 12: 24. https://doi.org/10.1186/1477-7827-12-24 